\title{
Downstream transport processes modulate the effects of environmental heterogeneity on riverine phytoplankton
}

\section{Graco-Roza, Caio}

2020

Graco-Roza , C , Santos , J B O , Huszar , V L M , Domingos , P , Soininen , J \& Marinho , M M 2020 , ' Downstream transport processes modulate the effects of environmental heterogeneity on riverine phytoplankton ' , The Science of the Total Environment , vol. 703 , 135519 . https://doi.org/10.1016/j.scitotenv.2019.135519

http://hdl.handle.net/10138/338297

https://doi.org/10.1016/j.scitotenv.2019.135519

cc_by_nc_nd

acceptedVersion

Downloaded from Helda, University of Helsinki institutional repository.

This is an electronic reprint of the original article.

This reprint may differ from the original in pagination and typographic detail.

Please cite the original version. 


\title{
Downstream transport processes modulate the effects of environmental heterogeneity on riverine phytoplankton
}

\author{
Caio Graco-Roza ${ }^{\text {a,c,*, }}$, Juliana B.O. Santos ${ }^{\text {b }}$, Vera L.M. Huszar ${ }^{\text {b }}$, Patrícia Domingos a , \\ Janne Soininen ${ }^{c}$, Marcelo Manzi Marinho ${ }^{a}$

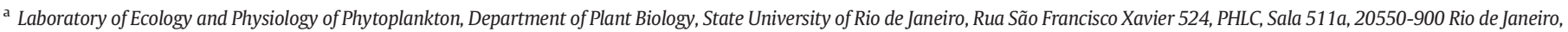 \\ Brazil \\ b Laboratory of Phycology, National Museum, Federal University of Rio de Janeiro, 20940-040 Rio de Janeiro, Brazil

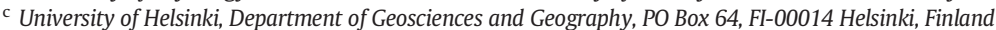

\section{H I G H L I G H T S}

- Environmental heterogeneity (EH) generally promotes community variation.

- Phytoplankton dispersal in rivers is modulated by flow conditions.

- Community distinctiveness highlights patterns of variation in space and time.

- Nutrient-enrichment promotes decrease in community distinctiveness.

- Higher dispersal masks the relationship between $\mathrm{EH}$ and community distinctiveness.

\section{G R A P H I C A L A B S T R A C T}

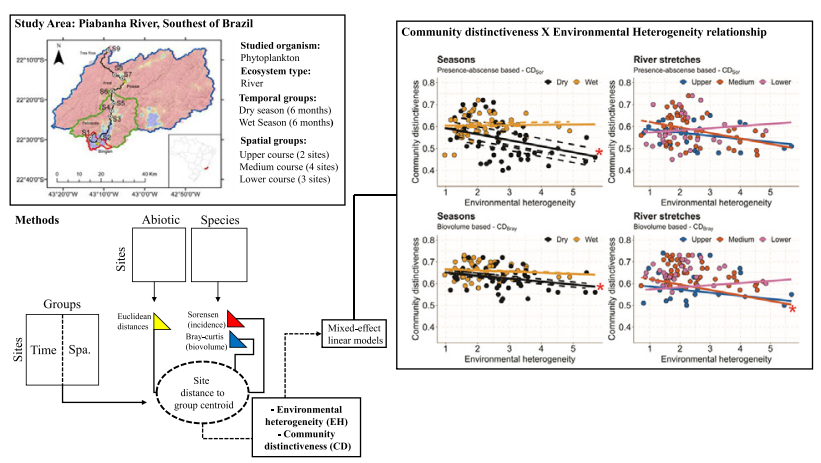

\begin{abstract}
A B S T R A C T
Environmental heterogeneity (EH) in space and time promotes niche-partition, which leads to high variation in biological communities, such as in algae. In streams, EH is highly related to the intensity of the water flow and may lead to community variation mainly during the low flow conditions. Despite the wide knowledge on the responses of phytoplankton communities to EH in lentic and semi-lentic systems, studies of riverine phytoplankton community variation are still scarce. Here, we first investigated the relationship between phytoplankton community variation and $\mathrm{EH}$ in different courses of the river and between seasons. We expected that under low or intermediate flow conditions, there is a positive correlation between community variation and EH. Alternatively, we did not expect any relationship between EH and community variation under high flow condition because stronger downstream transport would mask environmental filtering. We sampled nine sites monthly (May 2012 to April 2013) in a tropical river of Brazilian Southeast. We calculated EH from abiotic data whereas for community variation, here community distinctiveness $(C D)$, we used Sorensen $\left(\mathrm{CD}_{\text {Sor }}\right)$ and Bray-Curtis $\left(\mathrm{CD}_{\text {Bray }}\right)$ dissimilarities. Differences in $\mathrm{EH}, \mathrm{CD}_{\text {Sor }}$ and $\mathrm{CD}_{\text {Bray }}$ were tested at between-season and among-course levels. We found lower distinctiveness during the dry season when EH was the highest. Contrastingly, phytoplankton CD was the highest even when EH was low during the wet season. We found that this pattern raised from the increasing in individuals dispersal during the wet season, promoting mass effects. Finally, our results thus reject the first hypothesis and show a negative relationship between $\mathrm{EH}$ and distinctiveness. However, results support our
\end{abstract}

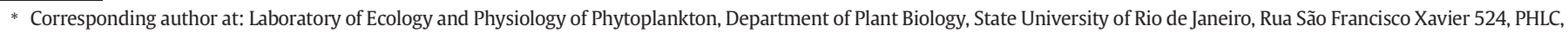
Sala 511a, 20550-900 Rio de Janeiro, Brazil.

E-mail address: caiogracor@gmail.com (C. Graco-Roza). 
alternative hypothesis and show that during the wet season, distinctiveness is not driven by EH. These results provide new insights into how $\mathrm{EH}$ drives community variation, being useful for both basic research about riverine algal communities and biomonitoring programs using phytoplankton communities as bioindicators.

(c) 2019 Elsevier B.V. All rights reserved.

\section{Introduction}

Spatial variation in biotic communities can stem from various processes including species dispersal, speciation, extinction, niche partitioning and biotic interactions (MacArthur and Wilson, 1967) of which balance depends on ecosystem type and species traits. Generally, microorganisms such as phytoplankton, are relatively well dispersed even over the globe due to their small size and high abundance that leads to their cosmopolitan or at least continental distributions (Green and Bohannan, 2006; Naselli-Flores and Padisák, 2016). High dispersal capacity supports a long-standing statement for microorganisms, that is 'everything is everywhere, but, the environment selects' (BaasBecking, 1934). Despite fairly wide knowledge about the dispersal capacity of microbial taxa in general (Fenchel and Finlay, 2004) the question of whether phytoplankton species show dispersal limitation at broad spatial scales still remains largely unresolved (Vanormelingen et al., 2009).

The spatial factors may have a distinct role over biotic communities also at much smaller spatial scales than at global or intercontinental scales typical for biogeographical studies. Mostly relevant at regional or landscape scales, metacommunity theory (Leibold et al., 2004) disentangles the importance of local (i.e., environmental variables or biotic interactions) and regional (i.e., dispersal limitation and mass effects) processes structuring spatially interacting communities. The balance between local environmental filtering and species dispersal typically varies between the organism strategies for growth and reproduction, and environmental settings leading to four main metacommunity archetypes: neutral model, species sorting, patch dynamics and mass effects (Chase and Leibold, 2003; Hubbell, 2001; Leibold et al., 2004; Leibold and Chase, 2018; Shmida and Wilson, 1985).

The importance of environmental filtering vs. dispersal processes typically also vary with spatial scales and, at broad spatial scales, dispersal limitation tends to be higher while species sorting and mass effects may prevail at intermediate or smaller scales (Astorga et al., 2012; Tonkin et al., 2018b). For example, some evidence suggests species sorting drives phytoplankton communities especially at intermediate spatial scales where dispersal limitation is weaker and the spatial scale is too large for the mass effects to take place (Huszar et al., 2015; Soininen, 2014), but this is still uncertain. Therefore, to understand the factors underlying the multiple metacommunity archetypes, the variation in community composition in space or time, is perhaps the most powerful concept (Viana et al., 2016). In the light of species sorting, it is expected that environmental heterogeneity (i.e., the spatial variation in environmental factors) would be directly related to the level of community variation (van der Velde et al., 2008).

There is both theoretical (Leibold et al., 2004) and some empirical (López-González et al., 2015; Thomaz et al., 2007; Thomaz et al., 2003) evidence showing that $\mathrm{EH}$ and $\beta$-diversity (i.e. community variation) are positively related. This has also been observed for phytoplankton in lakes (Alves-De-Souza et al., 2017; Maloufi et al., 2016), reservoir (Wojciechowski et al., 2017), floodplain (Bortolini et al., 2017a; Chaparro et al., 2018), and river systems (Wu et al., 2018). However, some studies also reported a negative or hump-shaped EHcommunity variation relationship (Bini et al., 2014; Heino et al., 2015a and references therein). In riverine communities, the lack of relationship between EH and community variation (Heino et al., 2013; Jyrkänkallio-Mikkola et al., 2016) has been reported to possibly result from mass effects, which would homogenize the community irrespective of the level of EH (Soininen et al., 2007a).

In streams, spatio-temporal patterns in $\mathrm{EH}$ are typically related to hydrology. Considering the constant longitudinal connectivity of running waters, $\mathrm{EH}$ would be lowest mainly in the periods of high flow (Bozelli et al., 2015) due to water chemistry homogenization promoted by river flow (Wetzel, 2001). For instance, freshwater phytoplankton in lentic systems is mostly controlled by bottom-up processes such as nutrient supply and light availability (Reynolds, 2006) whereas for riverine phytoplankton community, physical factors (e.g. water discharge, temperature, turbidity) (Descy et al., 2017) and downstream transport process (Lucas et al., 2009; Reynolds, 2000; Yu et al., 2015) take place because nutrients are often not a limiting factor for growth in streams. Concerning dispersal rates, longitudinal flow is one of the main drivers of microorganisms in flowing systems (Lampert and Sommer, 2007). Studies showed that among passive disperses (e.g. phytoplankton), watercourse distance might overcome other types of dispersion (e.g. overland, symmetric) and create a longitudinal pattern of species distribution (Devercelli et al., 2016; Liu et al., 2013). In addition, in dendritic network systems, the number of rivers connected to the main channel affect community resilience to disturbances (Altermatt and Fronhofer, 2018). This implies that the relationship between community variation and environmental conditions would also depend on the network area, because higher dispersal rates would increase the arrival of individuals and diminish extinction rates. It is also important to highlight that the increase in river flow might introduce non-planktonic species to the water column through downstream transport processes (Várbíró et al., 2018; Wang et al., 2018; Wang et al., 2014). This would increase stochasticity in distribution patterns and weaken the link between community composition and environmental conditions (Descy et al., 2012; Jamoneau et al., 2018).

Here, we first investigate the relationship between river phytoplankton community variation, or hereafter, community distinctiveness (see details below) and $\mathrm{EH}$ in different river courses and between wet and dry seasons. We hypothesized that under intermediate or low flow conditions in a dry season, phytoplankton community variation is positively correlated with $\mathrm{EH}$, because environmental filtering is expected to be strong when dispersal rates are so low that abundances are not affected by the arrival of new individuals (Heino et al., 2015a). Alternatively, under high flow conditions in a wet season, we do not expect any effect of EH on community variation, because stronger downstream transport processes increase stochasticity in species distributions and lessen environmental filtering while increasing the likelihood of mass effects. Finally, we examine the most important environmental drivers of phytoplankton distinctiveness in the river and disentangle the importance of downstream transport processes and environmental filtering in phytoplankton community variation.

\section{Materials and methods}

\subsection{Study area}

Piabanha river located in the Atlantic forest biome in Brazilian Southeast, has $80 \mathrm{~km}$ long and the drainage basin is approximately $4500 \mathrm{~km}^{2}$. The headwaters are at $1125 \mathrm{~m}$ altitude (Petrópolis city, Rio de Janeiro state), and drain to the medium valley of Paraíba do Sul river, crossing three municipalities with different population densities (Fig. 1). Population density data were obtained from Socioeconomic 


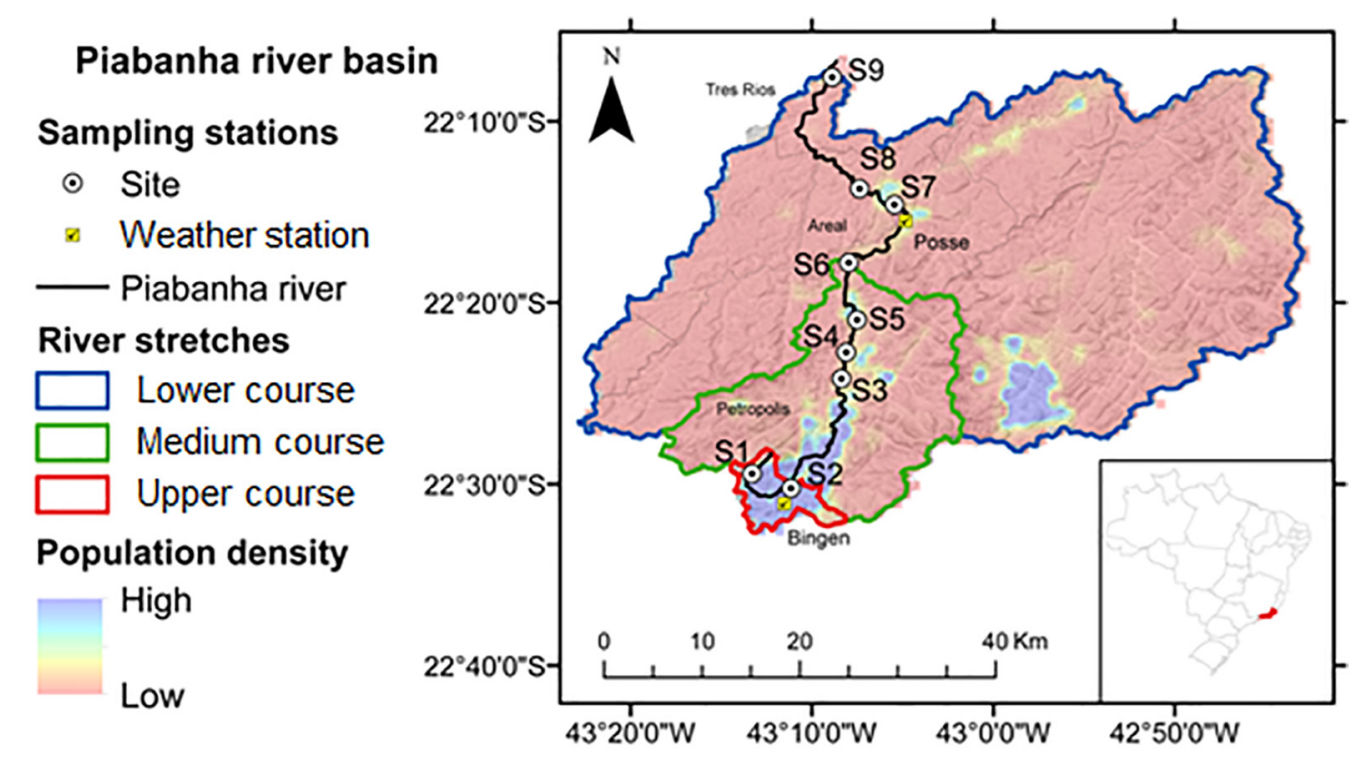

Elevational profile of Piabanha river

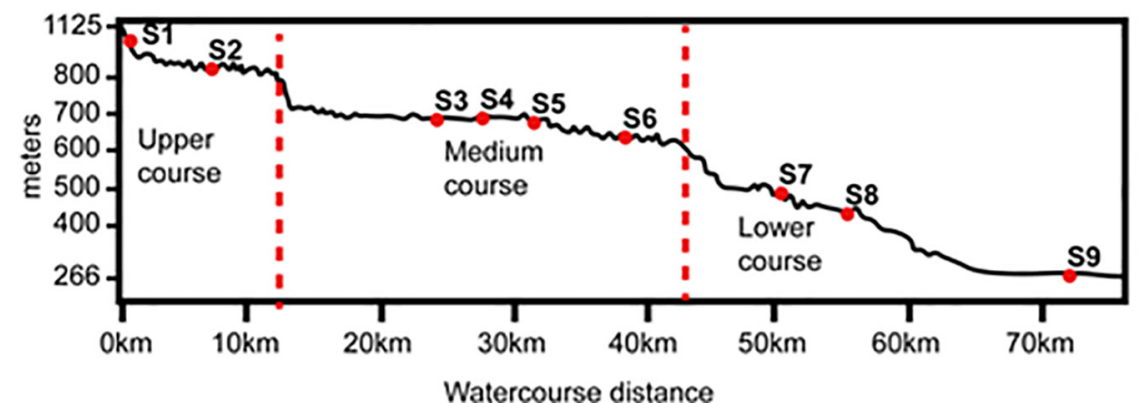

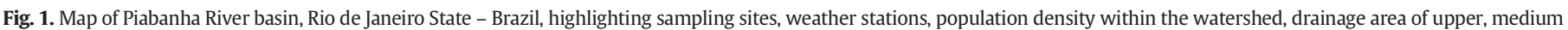
and lower course and elevation profile of the river.

Data and Application Center (Center for International Earth Science Information Network - CIESIN - Columbia University, 2017, see https://beta.sedac.ciesin.columbia.edu/data/set/gpw-v4-populationdensity-rev10).

We set three river stretches (lower, medium and upper courses) based on sharps slopes at the river elevation profile (Fig. 1). Hydrological features of each stretch were obtained through a digital elevation model (source: http://www.webmapit.com.br/inpe/topodata/) and processed in ArcGIS 10.5 with the Spatial Analyst package. Besides hydrological differences, the stretches also show different population densities with the upper course being the more populated in this study (Table 1).

\subsection{Sampling and laboratory analysis}

Monthly samples were taken in nine stations approximately every $6 \mathrm{~km}$ from headwaters to the mouth of Piabanha River between May2012 and April-2013 (Fig. 1). Data from two meteorological stations, close to the sampling sites, were used to characterize rainfall. We analyzed meteorological data up to 3 days before each campaign and observed a dry season from May to October and a wet season from November to April.

We took water samples in each station and each sampling occasion and kept these frozen (one or 2 weeks) until the laboratory analysis for ammonium $\left(\mathrm{N} \cdot \mathrm{NH}_{4}^{+}, \mathrm{mg} \mathrm{L}^{-1}\right)$, nitrate $\left(\mathrm{N} \cdot \mathrm{NO}_{3}^{-}, \mathrm{mg} \mathrm{L}^{-1}\right)$, total phosphorus (TP, $\mathrm{mg} \mathrm{L}^{-1}$ ) and soluble reactive phosphorus (SRP, $\mathrm{mg} \mathrm{L}^{-1}$ ). Water samples were filtered (except for total phosphorus analysis) using borosilicate filters (Whatman GF/C). Determinations of nutrient concentrations were performed following APHA, 1998. In the field, we measured temperature $\left({ }^{\circ} \mathrm{C}\right)$, dissolved oxygen ( $\mathrm{DO}, \mathrm{mg} \mathrm{L}^{-1}$ ) and turbidity by a multiparameter probe sonde (YSI model 600 QS). Water discharge (WD, $\mathrm{m}^{3} \mathrm{~s}^{-1}$ ) was measured with the SonTek RiverSurveyor - M9.

Subsurface samples of phytoplankton were collected with a bottle of $200 \mathrm{~mL}$ and fixed with Lugol-acetic solution. Phytoplankton population densities (ind $\mathrm{mL}^{-1}$ ) were estimated by using the sedimentation technique (Utermöhl (1958) under an inverted microscope (400× magnification, Olympus CKX41). Biovolume $\left(\mathrm{mm}^{3} \mathrm{~L}^{-1}\right)$ was estimated by multiplying the density of each population by the average volume, estimated from 20 random chosen individuals (whenever was possible), using the appropriate geometrical forms (Hillebrand, 1999; Sun and Liu, 2003).

Table 1

Main features of Piabanha river (RJ, Brazil) stretches.

\begin{tabular}{|c|c|c|c|c|c|}
\hline River stretch & Elevation range $(\mathrm{m})$ & Length $(\mathrm{km})$ & Mean slope ( $\mathrm{m}$ per $\mathrm{km})$ & Population density (ind $/ \mathrm{km}^{2}$ ) & Sampling points \\
\hline Upper course & $1125-825$ & 9.6 & 31.25 & 3172 & $\mathrm{~S} 1$ and S2 \\
\hline Medium course & $825-640$ & 32.5 & 0.57 & 412 & S3-S6 \\
\hline Lower course & $640-266$ & 36.3 & 10.30 & 165 & S7-S9 \\
\hline
\end{tabular}




\subsubsection{Data analysis}

A huge variety of community variation metrics has been used to understand the relationship between community variation and environmental heterogeneity (Anderson et al., 2011). Most of these metrics consist of pairwise dissimilarities, or even in some cases, one single value representing a group of multiple sites (Baselga, 2013). However, assessing community variation as the distinctiveness of each site or species from a focal sample or group instead of pairwise or multiple site metrics may provide some advantages in predicting spatial or temporal patterns (Legendre and De Cáceres, 2013; Legendre and Gauthier, 2014). This approach has also been used for estimating loss of native and gain of non-native species in a community (Cassey et al., 2008). Here, we measured community distinctiveness (CD) of each site as the distance to a group centroid using: i) Sørensen dissimilarity ( $\left.C D_{\text {Sor }}\right)$, based on phytoplankton incidence data (presence-absence) and, ii) Bray-Curtis dissimilarity $\left(\mathrm{CD}_{\text {Bray }}\right)$, based on phytoplankton biovolume. The first metric is more likely to reflect variation in species spatial distributions whereas the latter is more sensitive to environmental gradients in the study area (Declerck et al., 2011). We considered seasons and river stretches separately in the analyses and thus tested for differences between (i) dry and wet season and (ii) upper, medium and lower courses. We estimated the environmental heterogeneity $(\mathrm{EH})$ for each sample from Euclidean distances of standardized abiotic data (TP, SRP, $\mathrm{N} \cdot \mathrm{NO}_{3}^{-}$, $\mathrm{N} \cdot \mathrm{NH}_{4}^{+}, \mathrm{DO}$, turbidity, temperature and $\mathrm{pH}$ ). Because the lack of WD data in some sampling sites (i.e. S1, S2) or sampling months (i.e. September and November), we considered the mean values of the past 7 years as our local values, which implies that no temporal variation in WD is expected among these sites. Therefore, to avoid any bias in our analysis, we did not consider water discharge when estimating EH.

Differences in homogeneity of variances of environmental conditions, community composition and community biovolume between seasons or among river stretches were investigated through a permutation test of multivariate homogeneity of groups dispersions (PERMDISP; Anderson et al., 2006) through betadisper function within the R package vegan (Oksanen, 2015). This test considers the distance of individual observations to their group centroid and distances represent the amount of variation among samples. We also performed Levene's test through leveneTest function within the R package car (Fox et al., 2018) to check for differences in the variance of each abiotic variable between seasons and among river stretches. Levene's test is considered a univariate version of PERMDISP and was performed even when we did not find any differences in EH between courses or among stretches. Tukey's tests were further performed to detect significant differences among river stretches.

Because PERMDISP tests for homogeneity in variances, we applied a permutational analysis of variance called Adonis (Oksanen, 2015) to test for differences in community composition and biovolume between seasons, among river stretches and also their possible interactions. Pairwise Adonis was carried out to test for the differences among river stretches using the function pairwise.adonis2 within the $\mathrm{R}$ package pairwiseAdonis (Martinez Arbizu, 2019). In addition, similarity percentage tests (SIMPER) were used at classes and species level to identify which taxa explained most of dissimilarities among groups of samples. We used function simper within the R package vegan (Oksanen, 2015). Taxa that comprised $<0.2 \%$ of biovolume were removed to minimize the influence of rare or inadequately sampled taxa.

To disentangle the effect of environmental filtering on phytoplankton community variation we applied mixed-effects linear models with beta distribution family (Cribari-Neto and Zeileis, 2010) using the function gamlss within the R package gamlss (Stasinopoulos and Rigby, 2007). Firstly, we tested for the effects of seasonality in the relationship between $\mathrm{EH}$ and $\mathrm{CD}$ and included sampling month as a random factor in the model to account for the within-season multiple measures. Secondly, we tested for the spatial effects in the relationship between $\mathrm{EH}$ and $C D$ and included sampling site as a random factor in the model to account for the within-stretch multiple measures. Models were carried out using both species incidence and biovolume-based measures of $\mathrm{CD}$, totalizing four different models. Then, we determined the relative importance of each environmental variable to $\mathrm{CD}$ with Boosted Regression Trees (BRT) method. BRT is a machine learning ensemble method based on regression trees and boosting. The final BRT model can be considered as an additive regression model in which the individual terms are trees resulted from a stage wise algorithm (Elith et al., 2008). We fitted BRT models considering tree complexity $=5$, bagging fraction $=0.5$, learning rate $=0.001$ using the function gbm.step in the R package dismo (Hijmans and Elith, 2013) with a Gaussian error distribution. The percentage of explained deviance was assessed based on aggregated tenfold cross-validation with resubstitution (Elith et al., 2008).

Lastly, we used variation partitioning to explore the relative effects of spatial vs. environmental constraints on community composition. To control for the effects of seasonality, we performed analysis on community variation based on species incidence and biovolume considering all sampling sites and also separately at seasonal level. Dissimilarity matrices based on species incidence (i.e. Sorensen) and biovolume (i.e. Bray Curtis) were used as response variable and all the environmental variables were considered as predictors (now including WD). We then determined which of the environmental variables explained best community variation by applying a forward selection procedure on distance-based redundancy analysis through the functions dbrda and ordistep in vegan package. To account for the spatial autocorrelation among sites, spatial distances were extracted from asymmetrical eigenvectors maps (AEM; Blanchet et al., 2008) built from a connectivity matrix through the function aem within adespatial package (Dray et al., 2018). AEM model is an eigenfunction-based spatial filtering technique designed to model spatial structures produced by directional processes. We included the first eigenvector (AEM1) in our analysis because our sampling design comprises a single streamline with no samples in tributary rivers or connected lakes, which means that each site is connected to all the upstream sites above the focal site. It has been advocated that AEM1 describes the broadest spatial structure and encompasses the spatial variation in the whole study area (Blanchet et al., 2008; Yang et al., 2018). Finally, we partitioned the variation in community composition into the fractions explained by selected environmental variables vs. spatial factors for both seasons using the function varpart within vegan package. The variation partition (here partial redundancy analysis) is a multivariate extension of the linear regression that calculates the amount of variation explained (adjusted $R^{2}$ ) that can be attributed exclusively to one or the other set of environmental or spatial explanatory variables or their joint effects (Borcard et al., 1992; Cottenie, 2005). This procedure allowed us to investigate the effects of species sorting solely by the environment and solely by spatial processes (i.e., dispersal limitation or mass effects) on our communities.

\section{Results}

\subsection{Abiotic data}

During the dry season, nutrient values, except for $\mathrm{N} \cdot \mathrm{NO}_{3}^{-}$, were significantly $(p<0.05)$ higher, whereas temperature and WD were higher during the wet season (Fig. 2). Among the river stretches, lower courses of the river had higher values of temperature and WD, especially during the wet season, whereas nutrient concentrations, except $\mathrm{N} \cdot \mathrm{NO}_{3}^{-}$, were lower in the lower courses. Furthermore, EH was higher during the dry season than wet season (Table 2) with high variance in TP, $\mathrm{N} \cdot \mathrm{NH}_{4}^{+}$and DO (Table 3). EH did not show differences in homogeneity among stretches, although we found differences in some individual variables, namely $\mathrm{DO}, \mathrm{N} \cdot \mathrm{NH}_{4}^{+}$and temperature variances (Table 3).

\subsection{Biological data}

A total of 148 taxa belonging to seven taxonomic classes were registered. Bacillariophyceae, Chlorophyceae and Cyanobacteria contributed the most to the total number of species (80\%). With regards to biovolume, 

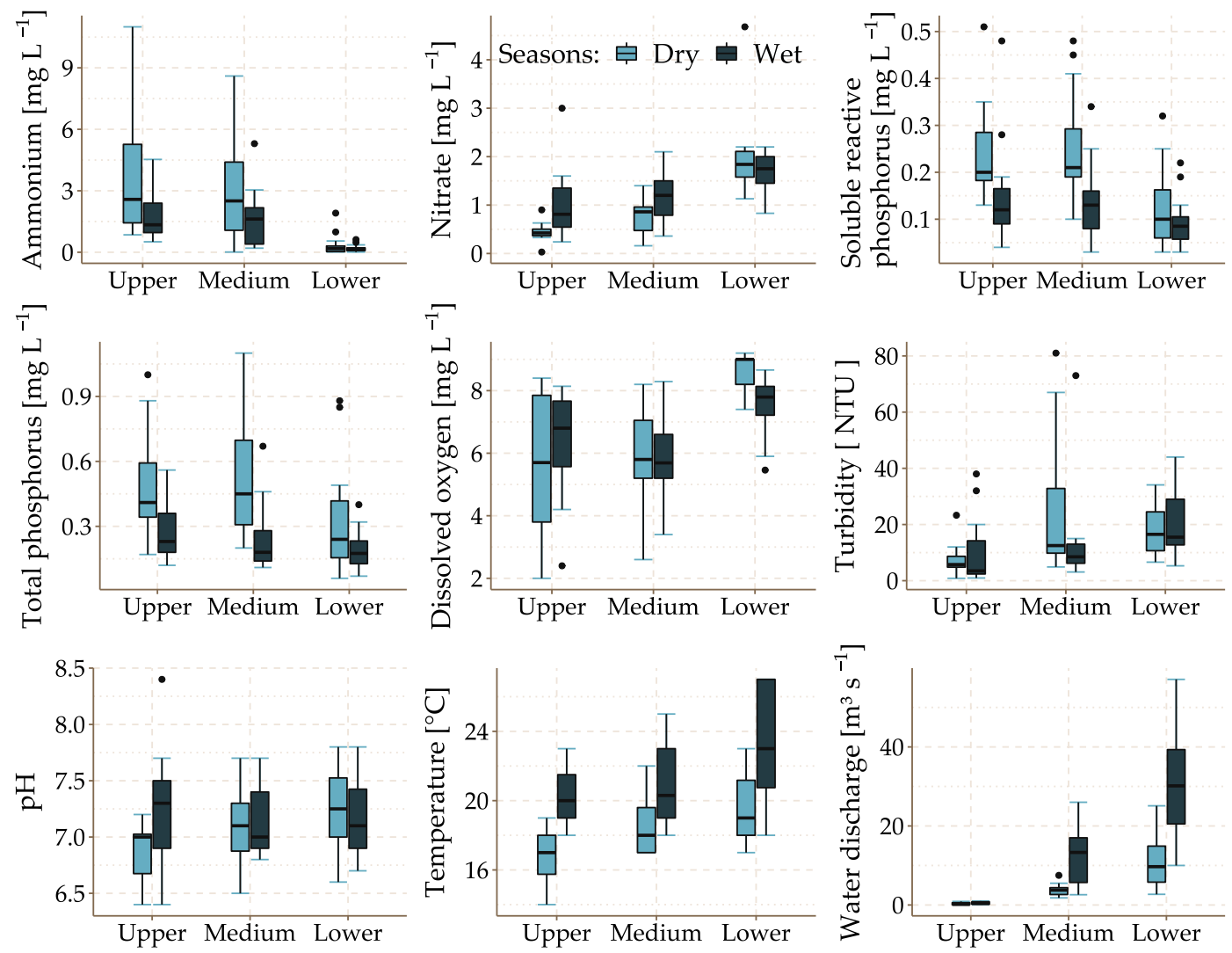



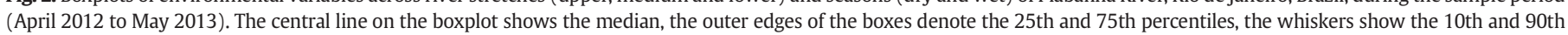
percentiles and any outliers are show as dots.

Bacillariophyceae (43\%) was the most representative, followed by Cyanobacteria (32\%), Euglenophyceae (14\%) and Chlorophyceae (6\%), totalizing $98 \%$ of the total biovolume. The highest total biovolume was observed during the dry season $\left(F_{1,98}=9.865, p<0.01\right)$ with a greater contribution of Pinnularia sp. 1 and Pseudanabaena sp. 4 (Table S1). Concerning the river stretches, the highest biovolume was attained by Pinnularia sp. 1 and Cymbella sp. in the medium course (Table S1), although no significant difference was observed in total biovolume among river stretches $\left(F_{2,97}=1.686, p=0.191\right)$. The complete list of species with mean biovolume across seasons and river stretches can be found in the supplementary material (Table S1).

The community differed between seasons both for incidence $\left(\mathrm{R}^{2}=\right.$ $0.06, \mathrm{p}<0.01)$ and biovolume-based $\left(\mathrm{R}^{2}=0.03, \mathrm{p}<0.01\right)$ dissimilarities (Table S2). Additionally, PERMDISP analysis showed highest heterogeneity of $\mathrm{CD}_{\text {Sor }}$ (incidence) and $\mathrm{CD}_{\text {Bray }}$ (biovolume-based) during the dry season (Table 2). The phytoplankton community differed between the upper course and the other river stretches when considering incidence dissimilarities (Table S2). In contrast, we observed differences in the communities among all the river stretches when considering species biovolume (Table S2). Nonetheless, we did not observe any difference in the variation of $\mathrm{CD}_{\text {sor }}$ among river stretches, but we found higher variance in $\mathrm{CD}_{\text {Bray }}$ at the upper course when compared to other stretches (Table 2). Additionally, SIMPER analysis revealed that Cyanobacteria accounted for $23 \%$ of seasonal differences in community variation, mainly related to species from the genus Pseudanabaena (Lauterborn) showing higher biovolume during the dry season rather than the wet season (Table S3). For river stretches, the reduction in Cyanobacteria biovolume along the river channel accounted for $27 \%$ (upper to medium courses) and 29\% (upper to lower courses) of the variation in the community (Table S3). A reduction in Bacillariophyceae biovolume, represented mainly by species from the genus Cymbella (Agardh) and Navicula (Bory de Saint-Vincent), accounted for $32 \%$ of the community variation between the medium and lower course (Table S3).

\subsection{Environmental heterogeneity $(E H) \times$ community distinctiveness $(C D)$}

There was a significant negative relationship between $\mathrm{EH}$ and $\mathrm{CD}_{\text {Sor }}$ $\left(\mathrm{R}^{2}=0.48, \mathrm{p}<0.01\right)$ and $\mathrm{CD}_{\text {Bray }}\left(\mathrm{R}^{2}=0.24, p=0.02\right)$ during the dry season, but no significant relationship during the wet season (Fig. 3). For the stretches, $\mathrm{EH}$ and $\mathrm{CD}_{\mathrm{Bray}}$ had a significant negative relationship

Table 2

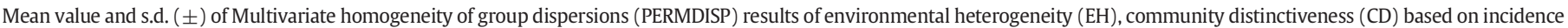
$\left(\mathrm{CD}_{\text {Sor }}\right)$ and based on biovolume $\left(\mathrm{CD}_{\text {Bray }}\right)$ in different seasons and river stretches in Piabanha River.

\begin{tabular}{|c|c|c|c|c|c|}
\hline & \multicolumn{2}{|l|}{ Season } & \multicolumn{3}{|l|}{ River stretch } \\
\hline & Dry season & Wet season & Upper course & Medium course & Lower course \\
\hline $\mathrm{EH}$ & $2.79( \pm 1.05)$ & $2.14( \pm 0.82)$ & $2.56( \pm 1.33)$ & $2.46( \pm 1.0)$ & $2.02( \pm 0.83)$ \\
\hline $\mathrm{CD}_{\text {Sor }}$ & $0.54( \pm 0.05)$ & $0.60( \pm 0.03)$ & $0.56( \pm 0.03)$ & $0.58( \pm 0.04)$ & $0.58( \pm 0.04)$ \\
\hline $\mathrm{CD}_{\text {Bray }}$ & $0.63( \pm 0.05)$ & $0.66( \pm 0.03)$ & $0.60( \pm 0.08)^{a}$ & $0.64( \pm 0.04)^{b}$ & $0.64( \pm 0.04)^{\mathrm{b}}$ \\
\hline
\end{tabular}

Significant values are in bold. Small letters refer to Tukey test in pairwise comparisons among river stretches. 
Table 3

Levene's test of the variation in environmental variables across seasons and river stretches.

\begin{tabular}{|c|c|c|c|c|}
\hline \multicolumn{5}{|l|}{ Seasons } \\
\hline \multirow{2}{*}{\multicolumn{2}{|c|}{ Environmental variables }} & \multicolumn{2}{|l|}{ Variance } & \multirow{2}{*}{$\begin{array}{l}\text { Levene's test } \\
\text { F-value }\end{array}$} \\
\hline & & Dry season & Wet season & \\
\hline \multicolumn{2}{|l|}{$\mathrm{pH}$} & 0.14 & 0.14 & 0.09 \\
\hline \multicolumn{2}{|l|}{ Temperature } & 3.99 & 8.35 & 9.99 \\
\hline \multicolumn{2}{|l|}{ Turbidity } & 289.71 & 186.32 & 0.70 \\
\hline \multicolumn{2}{|l|}{ Total phosphorus } & 0.07 & 0.02 & 17.51 \\
\hline \multicolumn{2}{|l|}{ Dissolved oxygen } & 3.92 & 2.05 & 6.17 \\
\hline \multicolumn{2}{|l|}{ Nitrate } & 0.64 & 0.35 & 0.71 \\
\hline \multicolumn{2}{|l|}{ Ammonium } & 7.05 & 1.57 & 9.40 \\
\hline \multicolumn{2}{|l|}{ Soluble reactive phosphorus } & 0.01 & 0.01 & 2.91 \\
\hline \multicolumn{5}{|l|}{ River stretches } \\
\hline \multirow[t]{2}{*}{ Environmental variables } & \multicolumn{3}{|c|}{ Variance } & $\begin{array}{l}\text { Levene's } \\
\text { test }\end{array}$ \\
\hline & $\begin{array}{l}\text { Upper } \\
\text { course }\end{array}$ & $\begin{array}{l}\text { Medium } \\
\text { course }\end{array}$ & $\begin{array}{l}\text { Lower } \\
\text { course }\end{array}$ & F-value \\
\hline $\mathrm{pH}$ & 0.21 & 0.11 & 0.12 & 0.39 \\
\hline Temperature & 5.67 & 5.57 & 10.99 & 3.23 \\
\hline Turbidity & 99.32 & 383.79 & 102.49 & 1.29 \\
\hline Total phosphorus & 0.05 & 0.07 & 0.04 & 1.58 \\
\hline Dissolved oxygen & 4.06 & 1.72 & 0.87 & 8.10 \\
\hline Nitrate & 0.39 & 0.22 & 0.42 & 0.02 \\
\hline Ammonium & 7.32 & 4.25 & 0.14 & 10.17 \\
\hline $\begin{array}{c}\text { Soluble reactive } \\
\text { phosphorus }\end{array}$ & 0.01 & 0.01 & 0.00 & 2.49 \\
\hline
\end{tabular}

Significant values are in bold.

$\left(\mathrm{R}^{2}=0.17, p=0.04\right)$ in the medium course. Detailed results of each model can be found in supplementary material (Table S4).

BRT models showed higher explained deviance of $C D$ across seasons than river stretches (Fig. 4), although environmental variables showed the same rank of importance in explaining phytoplankton variation. From the total of nine environmental variables considered in the BRT models, TP, $\mathrm{N} \cdot \mathrm{NH}_{4}^{+}$, WD and temperature explained together $>50 \%$ of the explained deviance for both $\mathrm{CD}_{\text {Sor }}$ and $\mathrm{CD}_{\text {Bray }}$ across seasons and river stretches (Fig. 4).

The distance-based RDA revealed that different subsets of environmental drivers were important across seasons, depending on the dissimilarity measure used (Fig. S1). The variation partition showed overall higher importance of environmental variables for both phytoplankton incidence and biovolume, although spatial distances showed significant contribution for community variation, especially when considering seasons separately (Table 4). During the dry season, we did not observe any pure spatial effect in phytoplankton community (Table 4). However, during the wet season, spatial factors had only weak importance on species incidence but they had comparable importance to environmental variables when considering species biovolume (Table 4).

\section{Discussion}

We investigated the effects of $\mathrm{EH}$ in the variation of phytoplankton community of river Piabanha across seasons and river stretches using two measures of community distinctiveness $(\mathrm{CD})$ based on species incidence $\left(\mathrm{CD}_{\text {Sor }}\right)$ and biovolume $\left(\mathrm{CD}_{\text {Bray }}\right)$. It is expected that in general, an increase in $\mathrm{EH}$ would increase community variation (Bortolini et al., 2017b; Maloufi et al., 2016; Wu et al., 2018). However, our results revealed that this is not the case in river Piabanha. We found that the seasonal differences in phytoplankton incidence, biovolume and also $\mathrm{EH}$ highlight the importance of river dynamics in shaping phytoplankton community. Our results provide evidence that even under high $\mathrm{EH}$, community variation may be low in sections more affected by anthropogenic activities or during the low flow periods. In addition, the observed spatial variation in phytoplankton biovolume were most likely
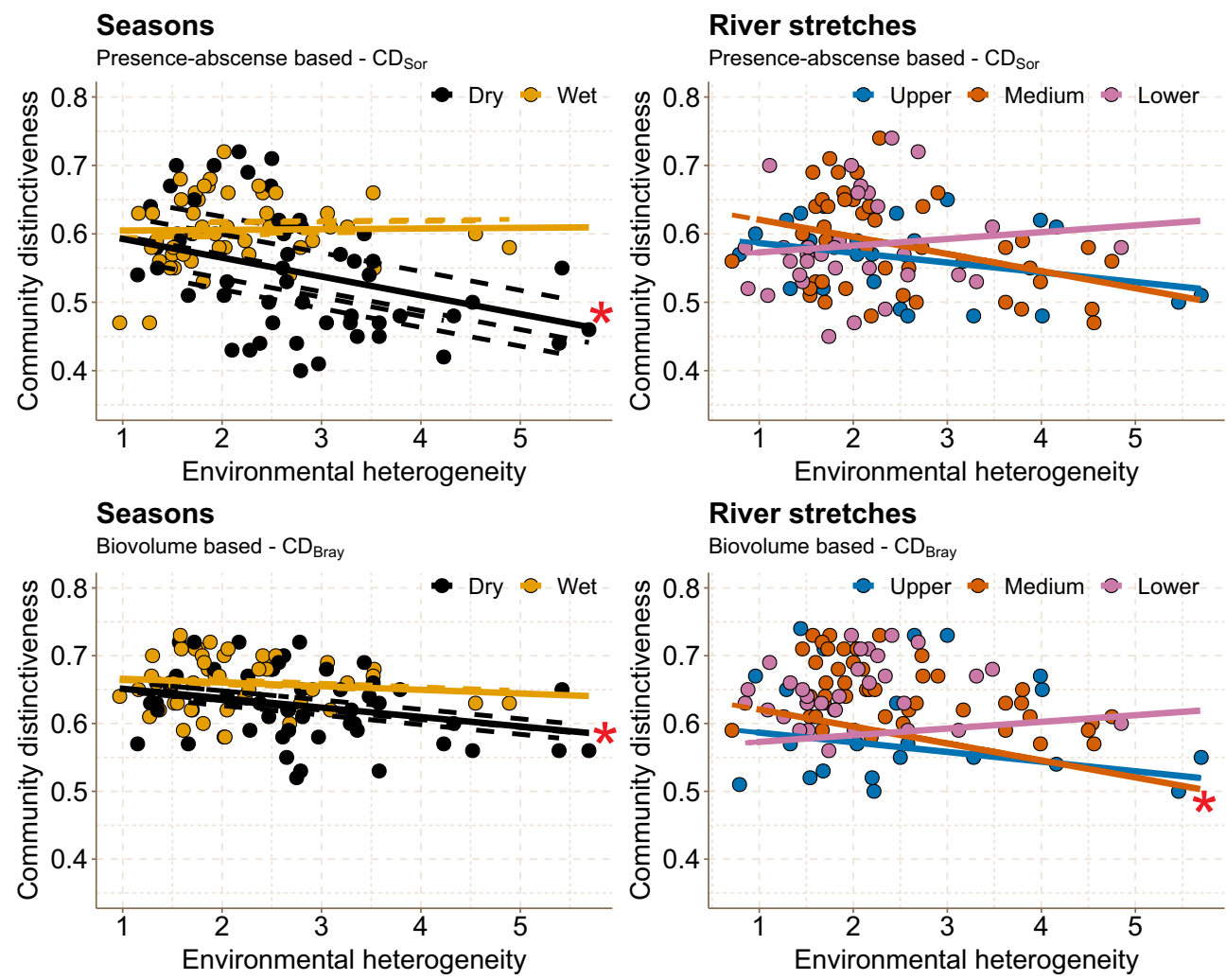

\section{River stretches}

Biovolume based $-\mathrm{CD}_{\text {Bray }}$

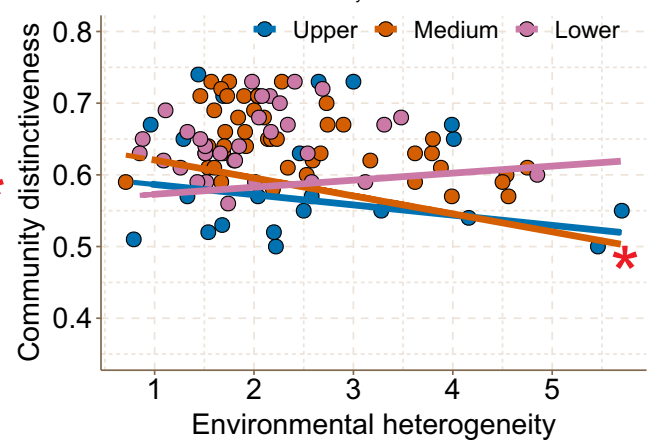

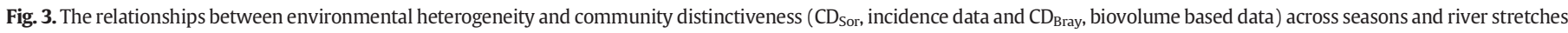

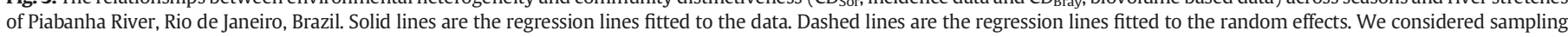
month as a random effect in the seasonal models (left panels) and sampling site as a random effect in the spatial models (right panels). ${ }^{*}$ Significant fits. 


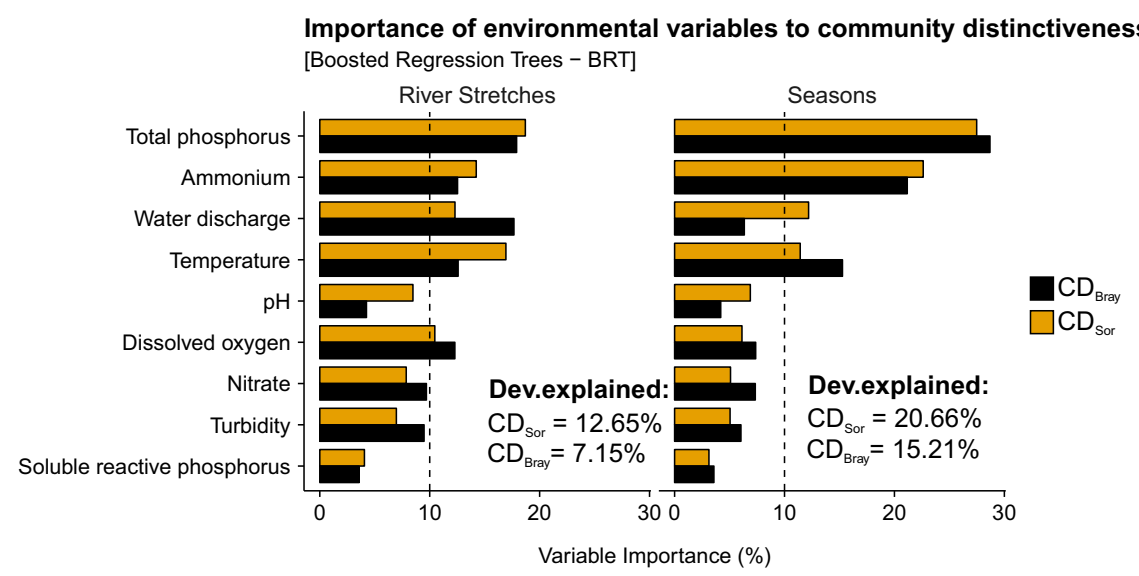

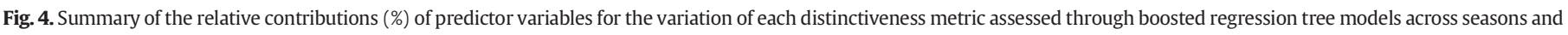
river stretches. The vertical dotted line indicates the arbitrary threshold of $10 \%$ to select the most important drivers.

result of both downstream transport process (i.e. species originating mainly from the upper course were found also in lower courses but with lower biovolume) and environmental filtering (e.g. dominance of Cyanobacteria under high nutrient concentrations), which suggests that both mass effects and species sorting may play roles in this system. Next, we will discuss our main findings in detail.

\subsection{Environmental heterogeneity}

In this study, EH varied between seasons due to the different hydrodynamics, showing lower values during the wet season when the exchange of material is higher because of the highest flow (Bozelli et al., 2015). This might stem from the observed reduction of the spatial variation and nutrient concentrations (except for $\mathrm{N} \cdot \mathrm{NO}_{3}^{-}$) during the wet season. In fact, the main loads of inorganic matter to Piabanha River are the wastewater discharge from the cities. Thus, the runoff promoted by the rainfall during the wet season is not the major factor for variability in nutrient concentrations, especially for paved urban areas. In this case, the increase in water level during the wet season promotes the dilution of nutrient concentrations from wastewater (Uhlmann, 1971; Zhu et al., 2007). Note that the nutrient concentrations were highest in the upper course, which is in the most populated city of the study (Table 1). Here, we note that the lack of spatial EH could result from anthropogenic impacts in the headwaters that act as a source of nutrients from the most impacted reaches to the downstream. This agrees with earlier studies that highlight the importance of river headwaters to water quality downstream (Alexander et al., 2007; Jamoneau et al., 2018; Yang et al., 2016). Such findings suggest that besides the hydrology, surrounding land use also play an important role in driving phytoplankton communities.

Table 4

Adjusted coefficients of determination ( $\mathrm{R}^{2} \mathrm{adj}$ ) of each component to explain the variation in phytoplankton incidence and biovolume. [a] \% explained solely by environmental conditions; [b] \% shared variation between the environment and space and [c] \% explained solely by space. Only components [a] and [c] are testable and significant values are in bold. [d] \% unexplained variance.

\begin{tabular}{lllll}
\hline & {$[\mathrm{a}]$} & {$[\mathrm{b}]$} & {$[\mathrm{c}]$} & {$[\mathrm{d}]$} \\
\hline $\begin{array}{c}\text { All sites } \\
\text { Incidence }\end{array}$ & $\mathbf{6 . 8}$ & 0.7 & $\mathbf{0 . 5}$ & 91.9 \\
Biovolume & $\mathbf{2 . 6}$ & 1.5 & 0.03 & 95.6 \\
Dry season & & & & \\
Incidence & $\mathbf{5 . 0}$ & 0.6 & $* *$ & 94.6 \\
Biovolume & $\mathbf{1 . 7}$ & 1.1 & 0.2 & 97 \\
Wet season & & & & \\
Incidence & $\mathbf{3 . 5}$ & 1.4 & $\mathbf{1 . 6}$ & 93.3 \\
Biovolume & $\mathbf{1 . 5}$ & 0.1 & $\mathbf{1 . 3}$ & 96 \\
\hline
\end{tabular}

** Values lower than zero are not shown.

\subsection{Environmental heterogeneity $\times$ community distinctiveness - seasons}

The hypothesis that under low flow conditions, phytoplankton community variation is positively correlated with $\mathrm{EH}$ was rejected, irrespective of the metric used (Sorensen or Bray Curtis). Instead, we observed a negative relationship between $\mathrm{CD}$ and EH during the dry season (Fig. 3), even if some earlier river studies found a positive relationship between EH and community variation (Jyrkänkallio-Mikkola et al., 2017) or no relationship (Heino et al., 2013; Jyrkänkallio-Mikkola et al., 2016). The reason for such a negative relationship is speculative at present, but it may stem from the fact that the higher environmental heterogeneity in our study is related to the highest nutrient concentrations, especially in the most populated reaches. In fact, BRT results revealed the importance of nutrients to phytoplankton community, especially the fact that the increase of TP affected negatively CD (Fig. S2). This finding emerged even though for riverine phytoplankton, physical factors such as turbidity and water discharge are often considered as the most important drivers of community variation (Descy et al., 2012, 2017; Soares et al., 2007). Furthermore, high P and N concentrations generally select for a small subset of species such as filamentous Cyanobacteria (Cardoso et al., 2017), and most importantly, leads to biotic homogenization (Wengrat et al., 2018). Consequently, it is reasonable that $\mathrm{EH}$ and $\mathrm{CD}$ were negatively related especially during the low flow periods when dispersal processes are not likely to affect species abundances more than environmental filtering (Bozelli et al., 2015; Heino et al., 2015b).

Our second hypothesis - under high flow conditions, there is no effect of EH in community variation - was accepted. The lack of relationship between $\mathrm{CD}$ and $\mathrm{EH}$ during the wet season indicates the interplay between resource availability and dispersal rates in riverine phytoplankton. During the wet season, nutrient concentrations were lower, water discharge was higher and not surprisingly, we observed lower EH. Somewhat surprising was that during the high flow periods, CD was the largest even if high among-site dispersal, denoted by the importance of spatial factors in variation partition (Table 4), should homogenize communities. It may be that high community variation stemmed from the fact that higher water discharge can drive phytoplankton communities either through settling patterns (Bowes et al., 2016; Engelhardt et al., 2004) or through the insertion of benthic species that are dislodged by the river flow and then occur as tychoplankton (Descy et al., 2017; John and Museum, 2013; Liu et al., 2013; Wang et al., 2014). Such new colonists would increase stochasticity (Abonyi et al., 2012; Devercelli et al., 2016) leading also to higher community variation. Collectively, this may lead to a lack of a relationship between environmental factors and community variation of planktonic species (Jamoneau et al., 2018) along with overall higher community variation observed here. 
4.3. Environmental heterogeneity $\times$ community distinctiveness - river stretches

We found lower $\mathrm{CD}_{\mathrm{Bray}}$ within the upper course mostly due to higher biovolume of Cyanobacteria under the highest nutrient concentrations, and a significant relationship between $\mathrm{EH}$ and $\mathrm{CD}_{\text {Bray }}$ within the medium course. In fact, the smaller streams, such as the ones that join to Piabanha headwaters, are not expected to contribute significantly to planktonic communities as rapid stream flow does not allow planktonic communities to develop (Allan and Castillo, 2007). Additionally, upstream communities that are less influenced by the new colonists, are generally driven more strongly by species sorting than dispersal effects (Jamoneau et al., 2018; Tonkin et al., 2018a). Furthermore, the efficient dispersal in the lower reaches should lead to a decrease in community distinctiveness because the constant arrival of individuals would homogenize communities (Gianuca et al., 2017). It has been advocated that river flow is the driving force behind riverine microorganismal dispersal (Lampert and Sommer, 2007) and may lead to mass effects (Sarremejane et al., 2017). On the other hand, higher water discharge can also intensify environmental filtering in some circumstances selecting species able to cope with intermittent flow (Tornbjerg et al., 2019). This suggests that the relationship between CD and EH should differ among stretches because both the environmental filtering and dispersal rates vary along the water channel (Descy et al., 2012; Jamoneau et al., 2018). In addition, contrary to as suggested in river continuum hypothesis (Vannote et al., 1980), the conditions in the middle stretches of the rivers rather than lower stretches seem to suit better for truly planktonic species (a.k.a. euplankton) and should be less influenced by the detached benthic algae (Reynolds and Descy, 1996; Reynolds et al., 1994; Soares et al., 2007).

Both theoretical (Soininen et al., 2007b) and empirical (Wetzel et al., 2012) evidence states that community similarity decreases along a spatial gradient. However, riverine passive dispersers such as phytoplankton are expected to show a constant drift to downstream direction (Tonkin et al., 2018a), and in some cases, it can overcome environmental filtering due to mass effects (Chaparro et al., 2018; Dong et al., 2016; Heino et al., 2015a). Results from pRDA (Table 4) showed that species sorting is the main metacommunity archetype behind the community assembly processes in the phytoplankton of Piabanha river. However, seasonality plays an important role in the balance between dispersal processes and environmental filtering. The importance of environmental and spatial factors controlling phytoplankton community assembly is under huge debate and it is still uncertain. Studies point that environment plays the most important role (Huszar et al., 2015; Soininen et al., 2011), but exceptions exists (e.g. Meier and Soininen, 2014). Here, we suggest that the observed lack of among-stretch differences in incidence based distinctiveness $\left(\mathrm{CD}_{\text {Sor }}\right)$ most likely results from the dynamics of running waters in terms of flow processes and stochastic extinctioncolonization processes (Schmera et al., 2018). Moreover, the dendritic structure of the rivers increases the exchange of individuals and, at some spatial extents, increases the community variation even within homogeneous environments (Altermatt and Fronhofer, 2018). Then, one can suggest that the highest variance in the biovolume $\left(\mathrm{CD}_{\text {Bray }}\right)$ in the upper course as well as the negative effect of $\mathrm{EH}$ in the medium course stems from the complexity of the dendritic structure of the rivers. Furthermore, the gradual loss of phytoplankton biovolume from the upper to the lower course (Table S3) and the variance in community biovolume explained jointly by environment and space during the wet season (Table 4) is a compelling evidence of downstream transport process carrying species from the source points to suboptimal conditions, revealing an interplay between dispersal (downstream transport) and environmental constraints (chemical homogenization) along the river channel.

In conclusion, our results show a negative effect of $\mathrm{EH}$ in community distinctiveness, but during the wet season, this effect was reduced due to species dispersal. These results provide new insights into the factors driving phytoplankton community variation in rivers by showing how downstream transport processes and nutrient enrichment modify the relationship with EH. Finally, future studies would benefit from examining riverine phytoplankton communities with combining large spatial extent with high sampling resolution in space and time, in order to detect the relative importance of downstream transport and $\mathrm{EH}$ on community variation.

\section{Data availability statement}

The data used in this study are not available in any database.

\section{Declaration of competing interest}

Authors declare no conflict of interest.

\section{Acknowledgments}

CGR PhD scholarship was funded by Fudação de Apoio a Pesquisa do Estado do Rio de Janeiro (FAPERJ) and by Coordenação de Aperfeiçoamento de Pessoal de Nível Superior (CAPES). MMM was partially supported by CNPq (303572/2017-5).

\section{Appendix A. Supplementary data}

Supplementary data to this article can be found online at https://doi. org/10.1016/j.scitotenv.2019.135519.

\section{References}

Abonyi, A., Leitão, M., Lançon, A.M., Padisák, J., 2012. Phytoplankton functional groups as indicators of human impacts along the river Loire (France). Hydrobiologia 698, 233-249. https://doi.org/10.1007/s10750-012-1130-0.

Alexander, R.B., Boyer, E.W., Smith, R.A., Schwarz, G.E., Moore, R.B., 2007. The role of headwater streams in downstream water quality. J. Am. Water Resour. Assoc. https://doi. org/10.1111/j.1752-1688.2007.00005.x.

Allan, J.D., Castillo, M.M., 2007. Stream ecology: Structure and function of running waters. Ecology. SpringerLink: Springer e-Books. Springer, Netherlands. https://doi.org/ $10.2307 / 2265800$.

Altermatt, F., Fronhofer, E.A., 2018. Dispersal in dendritic networks: ecological consequences on the spatial distribution of population densities. Freshw. Biol. 63, 22-32. https://doi.org/10.1111/fwb.12951.

Alves-De-Souza, C., Benevides, T.S., Santos, J.B.O., Von Dassow, P., Guillou, L., Menezes, M., 2017. Does environmental heterogeneity explain temporal $\beta$ diversity of small eukaryotic phytoplankton? Example from a tropical eutrophic coastal lagoon. J. Plankton Res. 39, 698-714. https://doi.org/10.1093/plankt/fbx026.

Anderson, M.J., Ellingsen, K.E., McArdle, B.H., Letters, E., 2006. Multivariate dispersion as a measure of beta diversity. Ecol. Lett. 9, 683-693. https://doi.org/10.1111/j.14610248.2006.00926.x.

Anderson, M.J., Crist, T.O., Chase, J.M., Vellend, M., Inouye, B.D., Freestone, A.L., Sanders, N.J., Cornell, H.V., Comita, L.S., Davies, K.F., Harrison, S.P., Kraft, N.J.B.B., Stegen, J.C., Swenson, N.G., 2011. Navigating the multiple meanings of $\beta$ diversity: a roadmap for the practicing ecologist. Ecol. Lett. 14, 19-28. https://doi.org/10.1111/j.14610248.2010.01552.x.

APHA, 1998. APHA: standard methods for the examination of water and wastewater. Am. Public Heal. Assoc. Water Work. Assoc. Environ. Fed. 552.

Astorga, A., Oksanen, J., Luoto, M., Soininen, J., Virtanen, R., Muotka, T., 2012. Distance decay of similarity in freshwater communities: do macro- and microorganisms follow the same rules? Glob. Ecol. Biogeogr. 21, 365-375. https://doi.org/10.1111/j.14668238.2011.00681.x.

Baas-Becking, L.G.M., 1934. Geobiologie of inleiding tot de milieukunde. van Stockum and Zoon, The Hague, Neth.

Baselga, A., 2013. Multiple site dissimilarity quantifies compositional heterogeneity among several sites, while average pairwise dissimilarity may be misleading Ecography (Cop.) 36, 124-128. https://doi.org/10.1111/j.1600-0587.2012.00124.x.

Bini, L.M., Landeiro, V.L., Padial, A.A., Siqueira, T., Heino, J., 2014. Nutrient enrichment is related to two facets of beta diversity for stream invertebrates across the United States. Ecology 95, 1569-1578. https://doi.org/10.1890/13-0656.1.

Blanchet, G., Legendre, P., Borcard, D., 2008. Forward selection of spatial explanatory variables. Ecology 89, 2623-2632. https://doi.org/10.1890/07-0986.1.

Borcard, D., Legendre, P., Drapeau, P., 1992. Partialling out the spatial component of ecological variation. Ecology https://doi.org/10.2307/1940179.

Bortolini, J.C., Pineda, A., Rodrigues, L.C., Jati, S., Velho, L.F.M., 2017a. Environmental and spatial processes influencing phytoplankton biomass along a reservoirs-riverfloodplain lakes gradient: a metacommunity approach. Freshw. Biol. 62 1756-1767. https://doi.org/10.1111/fwb.12986. 
Bortolini, J.C., Train, S., Rodrigues, L.C., 2017b. The variability in the hydrosedimentologica regime supports high phytoplankton diversity in floodplain: a 12-year survey of the upper Paraná River. J. Limnol. 76 (3). https://doi.org/10.4081/jlimnol.2017.1509 (2017)DO -

Bowes, M.J., Loewenthal, M., Read, D.S., Hutchins, M.G., Prudhomme, C., Armstrong, L.K. Harman, S.A., Wickham, H.D., Gozzard, E., Carvalho, L., 2016. Identifying multiple stressor controls on phytoplankton dynamics in the river Thames (UK) using highfrequency water quality data. Sci. Total Environ. 569-570, 1489-1499. https://doi. org/10.1016/j.scitotenv.2016.06.239.

Bozelli, R.L., Thomaz, S.M., Padial, A.A., Lopes, P.M., Bini, L.M., 2015. Floods decrease zooplankton beta diversity and environmental heterogeneity in an Amazonian floodplain system. Hydrobiologia 753, 233-241. https://doi.org/10.1007/s10750-015-2209-1.

Cardoso, S.J., Nabout, J.C., Farjalla, V.F., Lopes, P.M., Bozelli, R.L., Huszar, V.L.M.M., Roland, F., Joa, S.J.C., Lopes, P.M., Bozelli, R.L., Huszar, V.L.M.M., 2017. Environmental factors driving phytoplankton taxonomic and functional diversity in Amazonian floodplain lakes. Hydrobiologia 802, 115-130. https://doi.org/10.1007/s10750-017-3244-x.

Cassey, P., Lockwood, J.L., Olden, J.D., Blackburn, T.M., 2008. The varying role of population abundance in structuring indices of biotic homogenization. J. Biogeogr. 35, 884-892. https://doi.org/10.1111/j.1365-2699.2007.01827.x.

Center for International Earth Science Information Network - CIESIN - Columbia University, 2017. Gridded Population of the World, Version 4 (GPWv4): Population Density, Revision 10. [WWW Document]. NASA Socioecon. Data Appl. Cent, Palisades, NY https://doi.org/10.7927/H4JQ0XZW.

Chaparro, G., Horváth, Z., O’Farrell, I., Ptacnik, R., Hein, T., 2018. Plankton metacommunities in floodplain wetlands under contrasting hydrological conditions. Freshw. Biol. 63, 380-391. https://doi.org/10.1111/fwb.13076.

Chase, J.M., Leibold, M.A., 2003. Ecological Niches: Linking Classical and Contemporary Approaches. University of Chicago Press.

Cottenie, K., 2005. Integrating environmental and spatial processes in ecological community dynamics. Ecol. Lett. 8, 1175-1182.

Cribari-Neto, F., Zeileis, A., 2010. Package “betareg.”. J. Stat. Softw. 34 (2), 1-24. https:// doi.org/10.18637/jss.v034.i02.

Declerck, S.A.J., Coronel, J.S., Legendre, P., Brendonck, L., 2011. Scale dependency of processes structuring metacommunities of cladocerans in temporary pools of highAndes wetlands. Ecography (Cop.) 34, 296-305. https://doi.org/10.1111/j.1600 0587.2010.06462.x

Descy, J.P., Darchambeau, F., Lambert, T., Stoyneva-Gaertner, M.P., Bouillon, S., Borges, A.V., 2017. Phytoplankton dynamics in the Congo River. Freshw. Biol. 62, 87-101. https://doi.org/10.1111/fwb.12851.

Descy, J.-P., Leitao, M., Everbecq, E., Smitz, J.S., Deliege, J.-F., 2012. Phytoplankton of the river Loire, France: a biodiversity and modelling study. J. Plankton Res. 34, 120-135. https://doi.org/10.1093/plankt/fbr085.

Devercelli, M., Giri, F., Schneider, B., Scarabotti, P., Mayora, G., Schneider, B., Giri, F. 2016. Unravelling the role of determinism and stochasticity in structuring the phytoplanktonic metacommunity of the Paraná River floodplain. Hydrobiologia 764, 139-156. https://doi.org/10.1007/s10750-015-2363-5.

Dong, X., Li, B., He, F., Gu, Y., Sun, M., Zhang, H., Tan, L., Xiao, W., Liu, S., Cai, O., 2016. Flow directionality, mountain barriers and functional traits determine diatom metacommunity structuring of high mountain streams. Sci. Rep. https://doi.org 10.1038/srep24711.

Dray, S., Bauman, D., Blanchet, G., Borcard, D., Clappe, S., Guenard, G., Jombart, T., Larocque, G., Legendre, P., Madi, N., Wagner, H.H., 2018. Multivariate Multiscale Spatial Analysis. CRAN.

Elith, J., Leathwick, J.R., Hastie, T., 2008. A working guide to boosted regression trees. J. Anim. Ecol. 77, 802-813. https://doi.org/10.1111/j.1365-2656.2008.01390.x.

Engelhardt, C., Krüger, A., Sukhodolov, A., Nicklisch, A., 2004. A study of phytoplankton spatial distributions, flow structure and characteristics of mixing in a river reach with groynes. J. Plankton Res. 26, 1351-1366. https://doi.org/10.1093/plankt/fbh125.

Fenchel, T., Finlay, B.J., 2004. The ubiquity of small species: patterns of local and global diversity. Bioscience 54, 777. https://doi.org/10.1641/0006-3568(2004)054[0777: TUOSSP]2.0.CO;2.

Fox, J., Weisberg, S., Price, B., Adler, D., Bates, D., Baud-Bovy, G., 2018. Package “Car.” R Doc Gianuca, A.T., Declerck, S.A.J., Lemmens, P., De Meester, L., 2017. Effects of dispersal and environmental heterogeneity on the replacement and nestedness components of? diversity. Ecology 98, 525-533. https://doi.org/10.1002/ecy.1666.

Green, J., Bohannan, B.J.M., 2006. Spatial scaling of microbial biodiversity. Trends Ecol. Evol. https://doi.org/10.1016/j.tree.2006.06.012.

Heino, J., Grönroos, M., Ilmonen, J., Karhu, T., Niva, M., Paasivirta, L., 2013. Environmental heterogeneity and $\beta$ diversity of stream macroinvertebrate communities at intermediate spatial scales. Freshw. Sci. 32, 142-154. https://doi.org/10.1899/12-083.1.

Heino, J., Melo, A.S., Bini, L.M., 2015a. Reconceptualising the beta diversity-environmental heterogeneity relationship in running water systems. Freshw. Biol. https://doi.org/ $10.1111 /$ fwb.12502

Heino, J., Melo, A.S., Siqueira, T., Soininen, J., Valanko, S., Bini, L.M., 2015b. Metacommunity organisation, spatial extent and dispersal in aquatic systems: patterns, processes and prospects. Freshw. Biol. 60, 845-869. https://doi.org/10.1111/fwb.12533.

Hijmans, R.J., Elith, J., 2013. Species Distribution Modeling with R Introduction. October 71. https://doi.org/10.1016/S0550-3213(02)00216-X

Hillebrand, H., 1999. Biovolume calculation for Palagic and benthic microalgae. J. Phycol. 424, 403-424.

Hubbell, S.P., 2001. The Unified Neutral Theory of Biodiversity and Biogeography, Monographs in Population Biology. https://doi.org/10.1016/S0006-3207(02)00228-8.

Huszar, V.L.M., Nabout, J.C., Appel, M., Santos, J.B.O., Abe, D.S., Silva, L.H.S., 2015. Environmental and not spatial processes (directional and non-directional) shape the phytoplankton composition and functional groups in a large subtropical river basin. J. Plankton Res. 37, 1190-1200. https://doi.org/10.1093/plankt/fbv084.
Jamoneau, A., Passy, S.I., Soininen, J., Leboucher, T., Tison-Rosebery, J., 2018. Beta diversity of diatom species and ecological guilds: response to environmental and spatial mechanisms along the stream watercourse. Freshw. Biol. 63, 62-73. https://doi.org/ $10.1111 /$ fwb. 12980

John, D.M., Museum, N.H., 2013. The Freshwater algal flora of the British Isles: an identification guide to freshwater and terrestrial algae. Choice Rev. Online 40. https://doi. org/10.5860/choice.40-3394 40-3394-40-3394.

Jyrkänkallio-Mikkola, J., Heino, J., Soininen, J., 2016. Beta diversity of stream diatoms at two hierarchical spatial scales: implications for biomonitoring. Freshw. Biol. 61, 239-250. https://doi.org/10.1111/fwb.12697.

Jyrkänkallio-Mikkola, J., Meier, S., Heino, J., Laamanen, T., Pajunen, V., Tolonen, K.T., Tolkkinen, M., Soininen, J., 2017. Disentangling multi-scale environmental effects on stream microbial communities. J. Biogeogr. 44, 1512-1523. https://doi.org/10.1111/jbi.13002.

Lampert, W., Sommer, U., 2007. The individual in its habitat. Limnoecology Ecol. lakes streams 33-88.

Legendre, P., De Cáceres, M., 2013. Beta diversity as the variance of community data: dissimilarity coefficients and partitioning. Ecol. Lett. 16, 951-963. https://doi.org/ 10.1111/ele.12141.

Legendre, P., Gauthier, O., 2014. Statistical methods for temporal and space-time analysis of community composition data. Proc. R. Soc. B Biol. Sci. 281, 20132728. https://doi. org/10.1098/rspb.2013.2728.

Leibold, M.A., Chase, J.M., 2018. Metacommunity Ecology. Metacommunity Ecol 59. https://doi.org/10.1111/j.1549-8719.2010.00043.x.

Leibold, M.A., Holyoak, M., Mouquet, N., Amarasekare, P., Chase, J.M., Hoopes, M.F., Holt, R.D., Shurin, J.B., Law, R., Tilman, D., Loreau, M., Gonzalez, A., 2004. The metacommunity concept: a framework for multi-scale community ecology. Ecol. Lett. 7, 601-613. https://doi.org/10.1111/j.1461-0248.2004.00608.x

Liu, J., Soininen, J., Han, B.P., Declerck, S.A.J., 2013. Effects of connectivity, dispersal directionality and functional traits on the metacommunity structure of river benthic diatoms. J. Biogeogr. 40, 2238-2248. https://doi.org/10.1111/jbi.12160.

López-González, C., Presley, S.J., Lozano, A., Stevens, R.D., Higgins, C.L., Celia, L., Presley, S.J., Lozano, A., Stevens, R.D., Higgins, C.L., López-González, C., Presley, S.J., Lozano, A., Stevens, R.D. Higgins, C.L, Celia, L. Presley, S.J. Lozano, A Stevens, R.D., Higgins, C.L, 2015. Ecological biogeography of Mexican bats: the relative contributions of habitat heterogeneity, beta diversity, and environmental gradients to species richness and composition patterns. Ecography (Cop.) 38, 261-272. https://doi.org/10.1111/ecog.00813.

Lucas, L.V., Thompson, J.K., Brown, L.R., 2009. Why are diverse relationships observed between phytoplankton biomass and transport time? Limnol. Oceanogr. 54, 381-390. https://doi.org/10.4319/lo.2009.54.1.0381.

MacArthur, R.H., Wilson, E.O., 1967. The theory of island biogeography. Monogr. Popul. Biol. https://doi.org/10.2307/1796430.

Maloufi, S., Catherine, A., Mouillot, D., Louvard, C., Ec, C., Couté, A., Bernard, C., Troussellier, M., 2016. Environmental heterogeneity among lakes promotes hyper $\beta$-diversity across phytoplankton communities. Freshw. Biol. 61, 633-645. https://doi.org/ $10.1111 /$ fwb.12731.

Martinez Arbizu, P., 2019. pairwiseAdonis: Pairwise Multilevel Comparison Using Adonis. R Packag. Version 0.3 .

Meier, S., Soininen, J., 2014. Phytoplankton metacommunity structure in subarctic rock pools. Aquat. Microb. Ecol. https://doi.org/10.3354/ame01711.

Naselli-Flores, L., Padisák, J., 2016. Blowing in the wind: how many roads can a phytoplanktont walk down? A synthesis on phytoplankton biogeography and spatial processes. Hydrobiologia 764, 303-313. https://doi.org/10.1007/s10750-015-2519-3.

Oksanen, J., 2015. Vegan: ecological diversity. 1, 1-12. https://doi.org/10.1029/ 2006JF000545.

Reynolds, C., Descy, J., 1996. The production biomass and structure of phytoplankton in large rivers. Arch. Hydrobiol. 113, 161-187. https://doi.org/10.1127/lr/10/1996/161.

Reynolds, C.S., 2000. Hydroecology of river plankton the role of variability in channel flow. Hydrol. Process. 14, 3119-3132. https://doi.org/10.1002/1099-1085(200011/ 12)14:16/17<3119::AID-HYP137>3.0.CO;2-6.

Reynolds, C.S., 2006. The Ecology of Phytoplankton, the Ecology of Phytoplankton. Cambridge University Press, Cambridge https://doi.org/10.1017/CBO9780511542145.

Reynolds, C.S., Descy, J.P., Padisák, J., 1994. Are phytoplankton dynamics in rivers so different from those in shallow lakes? Hydrobiologia 289, 1-7. https://doi.org/10.1007/ BF00007404.

Sarremejane, R., Cañedo-Argüelles, M., Prat, N., Mykrä, H., Muotka, T., Bonada, N., 2017. Do metacommunities vary through time? Intermittent rivers as model systems. J. Biogeogr. 44, 2752-2763. https://doi.org/10.1111/jbi.13077.

Schmera, D., Árva, D., Boda, P., Bódis, E., Bolgovics, Á., Borics, G., Csercsa, A., Deák, C., Krasznai, E., Lukács, B.A., Mauchart, P., Móra, A., Sály, P., Specziár, A., Süveges, K., Szivák, I., Takács, P., Tóth, M., Várbíró, G., Vojtkó, A.E., Erős, T., 2018. Does isolation influence the relative role of environmental and dispersal-related processes in stream networks? An empirical test of the network position hypothesis using multiple taxa. Freshw. Biol. 63, 74-85. https://doi.org/10.1111/fwb.12973.

Shmida, A., Wilson, M.V., 1985. Biological determinants of species diversity. J. Biogeogr. 12 (1). https://doi.org/10.2307/2845026.

Soares, M.C.S., Huszar, V.L.M., Roland, F., 2007. Phytoplankton dynamics in two tropical rivers with different degrees of human impact (Southeast Brazil). River Res. Appl. 23, 698-714. https://doi.org/10.1002/rra.987.

Soininen, J., 2014. A quantitative analysis of species sorting across organisms and ecosystems. Ecology 95, 3284-3292. https://doi.org/10.1890/13-2228.1.sm

Soininen, J., Kokocinski, M., Estlander, S., Kotanen, J., Heino, J., 2007a. Neutrality, niches, and determinants of plankton metacommunity structure across boreal wetland ponds. Ecoscience 14, 146-154. https://doi.org/10.2980/1195-6860.

Soininen, J., McDonald, R., Hillebrand, H., 2007b. The distance decay of similarity in ecological communities. Ecography (Cop.) https://doi.org/10.1111/j.09067590.2007.04817.x 
Soininen, J., Korhonen, J.J., Karhu, J., Vetterli, A., 2011. Disentangling the spatial patterns in community composition of prokaryotic and eukaryotic lake plankton. Limnol. Oceanogr. 56, 508-520. https://doi.org/10.4319/lo.2011.56.2.0508.

Stasinopoulos, D.M., Rigby, R.A., 2007. Generalized additive models for location scale and shape (GAMLSS) in R. J. Stat. Softw. https://doi.org/10.18637/jss.v023.i07.

Sun, J., Liu, D., 2003. Geometric models for calculating cell biovolume and surface area for phytoplankton. J. Plankton Res. 25, 1331-1346. https://doi.org/10.1093/plankt/ fbg096.

Thomaz, S.M., Souza, D.C., Bini, L.M., 2003. Species richness and beta diversity of aquatic macrophytes in a large subtropical reservoir (Itaipu reservoir, Brazil): the influence of limnology and morphometry. Hydrobiologia 505, 119-128. https://doi.org/ 10.1023/B:HYDR.0000007300.78143.e1.

Thomaz, S.M., Bini, L.M., Bozelli, R.L., 2007. Floods increase similarity among aquatic habitats in river-floodplain systems. Hydrobiologia 579, 1-13. https://doi.org/10.1007/ s10750-006-0285-y.

Tonkin, J.D., Altermatt, F., Finn, D.S., Heino, J., Olden, J.D., Pauls, S.U., Lytle, D.A., Altermatt, F., Finn, D.S., Heino, J., Pauls, S.U., Lytle, D.A., 2018a. The role of dispersal in river network metacommunities: patterns, processes, and pathways. Freshw. Biol. 63, 141-163. https://doi.org/10.1111/fwb.13037.

Tonkin, J.D., Heino, J., Altermatt, F., 2018b. Metacommunities in river networks: the importance of network structure and connectivity on patterns and processes. Freshw. Biol. 63, 1-5. https://doi.org/10.1111/fwb.13045.

Tornbjerg, H., Andersen, H.E., Riis, T., Baattrup-Pedersen, A., Thodsen, H., Wu, N., Thodsen, H., Andersen, H.E., Tornbjerg, H., Baattrup-Pedersen, A., Riis, T., 2019. Flow regimes filter species traits of benthic diatom communities and modify the functional features of lowland streams - a nationwide scale study. Sci. Total Environ. 651, 357-366. https://doi.org/10.1016/j.scitotenv.2018.09.210.

Uhlmann, D., 1971. Influence of dilution, sinking and grazing rate on phytoplankton populations of hyperfertilized ponds and micro-ecosystems. SIL Commun. 1953-1996. 19, pp. 100-124. https://doi.org/10.1080/05384680.1971.11903925.

Utermöhl, H., 1958. Zur Vervollkommnung der quantitativen Phytoplankton-Methodik: Mit 1 Tab. Schweizerbart, Stuttgart.

Vannote, R.L., Minshall, G.W., Cummins, K.W., Sedell, J.R., Cushing, C.E., 1980. The river continuum concept. Can. J. Fish. Aquat. Sci. 37, 130-137. https://doi.org/10.1139/ f80-017.

Vanormelingen, P., Verleyen, E., Vyverman, W., 2009. In: Foissner, W., Hawksworth, D.L. (Eds.), The Diversity and Distribution of Diatoms: From Cosmopolitanism to Narrow Endemism BT - Protist Diversity and Geographical Distribution. Springer Netherlands, Dordrecht, pp. 159-171. https://doi.org/10.1007/978-90-481-2801-3_12.

Várbíró, G., Padisák, J., Nagy-László, Z., Abonyi, A., Stanković, I., Gligora Udovič, M., B-Béres, V., Borics, G., 2018. How length of light exposure shapes the development of riverine algal biomass in temperate rivers? Hydrobiologia 809, 53-63. https://doi.org/ 10.1007/s10750-017-3447-1. van der Velde, G., Chase, J.M., Leibold, M.A., 2008. Ecological niches. Linking classical and contemporary approaches. Crustaceana. University of Chicago Press, p. 1023. https:// doi.org/10.1163/156854008X354894.

Viana, D.S., Figuerola, J., Schwenk, K., Manca, M., Hobæk, A., Mjelde, M., Preston, C.D., Gornall, R.J., Croft, J.M., King, R.A., Green, A.J., Santamaría, L., 2016. Assembly mechanisms determining high species turnover in aquatic communities over regional and continental scales. Ecography (Cop.) 39, 281-288. https://doi.org/10.1111/ecog.01231.

Wang C., Li, X, Lai, Z Li, Y Dauta, A. Lek, S. 2014 Patterning and predicting phytoplankton assemblages in a large subtropical river. Fundam. Appl. Limnol./Arch. für Hydrobiol. 185, 263-279. https://doi.org/10.1127/fal/2014/0684.

Wang, C., B-Béres, V., Stenger-Kovács, C., Li, X., Abonyi, A., 2018. Enhanced ecological indication based on combined planktic and benthic functional approaches in large river phytoplankton ecology. Hydrobiologia 818, 163-175. https://doi.org/10.1007/ s10750-018-3604-1.

Wengrat, S., Padial, A.A., Jeppesen, E., Davidson, T.A., Fontana, L., Costa-Böddeker, S. Bicudo, D.C., 2018. Paleolimnological records reveal biotic homogenization driven by eutrophication in tropical reservoirs. J. Paleolimnol. 60, 299-309. https://doi.org/ 10.1007/s10933-017-9997-4.

Wetzel, C.E., de Bicudo, D.C., Ector, L., Lobo, E.A., Soininen, J., Landeiro, V.L., Bini, L.M., 2012 Distance decay of similarity in Neotropical diatom communities. PLoS One 7. https:// doi.org/10.1371/journal.pone.0045071.

Wetzel, R.G., 2001. Limnology: Lake and river ecosystems. J. Phycol. https://doi.org/ 10.1046/j.1529-8817.2001.37602.x.

Wojciechowski, J., Heino, J., Bini, L.M., Padial, A.A., 2017. Temporal variation in phytoplankton beta diversity patterns and metacommunity structures across subtropical reservoirs. Freshw. Biol. 62, 751-766. https://doi.org/10.1111/fwb.12899.

Wu, N., Qu, Y., Guse, B., Makarevičiūtė, K., To, S., Riis, T., Fohrer, N., 2018. Hydrological and environmental variables outperform spatial factors in structuring species, trait composition, and beta diversity of pelagic algae. Ecol. Evol. 8, 2947-2961. https://doi. org/10.1002/ece3.3903.

Yang, H., Wang, G., Wang, L., Zheng, B., 2016. Impact of land use changes on water quality in headwaters of the three gorges reservoir. Environ. Sci. Pollut. Res. 23, 11448-11460. https://doi.org/10.1007/s11356-015-5922-4.

Yang, Y., Niu, H., Xiao, L., Lin, Q., Han, B.P., Naselli-Flores, L., 2018. Spatial heterogeneity of spring phytoplankton in a large tropical reservoir: could mass effect homogenize the heterogeneity by species sorting? Hydrobiologia 819, 109-122. https://doi.org/ 10.1007/s10750-018-3651-7.

Yu, Q., Chen, Y., Liu, Z., van de Giesen, N., Zhu, D., 2015. The influence of a eutrophic lake to the river downstream: spatiotemporal algal composition changes and the driving factors. Water (Switzerland) 7, 2184-2201. https://doi.org/10.3390/w7052184.

Zhu, G., Qin, B., Gao, G., Zhang, L., Luo, L., Zhang, Y., 2007. Effects of hydrodynamics on phosphorus concentrations in water of Lake Taihu, a large, shallow, eutrophic lake of China. Hydrobiologia 581, 53-61. https://doi.org/10.1007/s10750-006-0519-z. 